\title{
FOUNDATIONS OF TROPICAL AGRICULTURE
}

\author{
By Prof. C. W. WardlaW, \\ University of Manchester (Formerly of the Imperial College cF Tropical Agriculture)
}

\footnotetext{
“' 'You must certainly have a vast estate,' said Candide to the Turk.

" 'I have no more than twenty acres of ground,' said he, 'the whole of which I cultivate myself with the help of my children; and by our labour we avoid three great evils, idleness, vice and want.'

“'Elevated stations,' said Pangloss, 'are very dangerous, according to the testimonies of almost all philosophies.'

“'I know,' said Candide, 'WE MUST CULTIVATE OUR GARDEN.","
}

VoltaIre.

\section{Imperial College of Tropical Agriculture, TRINIDAD}

Via cilendi haud facilis

$\mathrm{T}$ HE Imperial College of Tropical Agriculture in Trinidad was founded as the West Indian Agricultural College in 1921, to provide instruction in tropical agriculture and in the cultivation and preparation for market of tropical produce of every kind, and also to continue the work of the Imperial Department of Agriculture for the West Indies. In 1924 the name was changed to "The Imperial College of Tropical Agriculture". Two years later the College was incorporated by Royal Charter, and in the following year it received the patronage of M.H. the King. It is now the recognized centre for postgraduate training in tropical agriculture for the agricultural services of the Colonial Empire.

\section{The Oldest Industry}

As an institution for teaching and research the Imperial College of Tropical Agriculture is still in its first youth. Yet its roots are deep, for it has assimilated to itself the oldest and most honourable traditions in the world : man's need to till the soil and make it bring forth abundantly.

The way of the cultivator is hard. In the realm of agriculture man enjoys at best but a qualified success. In the Middle Ages, when famines and plagues periodically swept the face of whole continents, the heart-breaking vicissitudes of agriculture were recognized and passively accepted as being something in the nature of things, to be tolerated with patience and fortitude. To-day we still recognize the endless complexities and difficulties of agriculture, but our mood is no longer one of submission: we know that its problems, be they ever so complex, are not insoluble. With the passage of time science, in her many forms and even in her youngest branches, has been recruited to the aid of the oldest industry; over the whole world agricultural industries are being succoured and assisted as never before. Resignation in the face of famines, plagues and kindred agrarian mishaps, is no longer conceivable. The combination of the methods of science with the age-old art of the cultivator constitutes a new and unprecedented phase in human endeavour, and we strive with the heartening assurance that in spite of all difficulties we shall yet venture through adversity to success.

\section{From Cancer to CAPRICORN}

The citizens of medieval Europe who used spices from the distant Orient to preserve and give flavour to their food, and knew something of the strange exotic merchandise that came by caravan and quinquereme from the vast and little-known world beyond the Mediterranean basin, were yet entirely unaware of the enormous wealth that remained-and, be it said, to this day still remains - to be exploited in the tropical belt. That a swamp reed with a sweetish sap would one day be the basis of a major industry the world over; that bananas, in whose shade wise men of the East sat in pious contemplation, would give rise to a marvellous industry in the New World; that citrus fruits from the Orient would find their way to all lands where the hot sun beats down; and that the many new plants, maize, potatoes, tobacco, to mention only a few discovered by the Conquistadores in the New World, would become infinitely valuable sources of food in the Old : all these, and a hundred others, of the wonderful possibilities that lay untouched between the bounds of Cancer and Capricorn were unknown to our medieval ancestors, yet but awaited the day when men would set out in search of new lands, to bring back undreamed-of spoil.

More often than not the gold that the Conquistadores sought with such incredible energy and ferocity failed to materialize. Nor, with some rare exceptions, did they realize that the real and enduring value of their discoveries and conquests lay, not in mines, but in those vast tracts of rich agricultural territory found by them in that equatorial belt which imaginative geographers have described as the Torrid Zone. Here, indeed, in the 


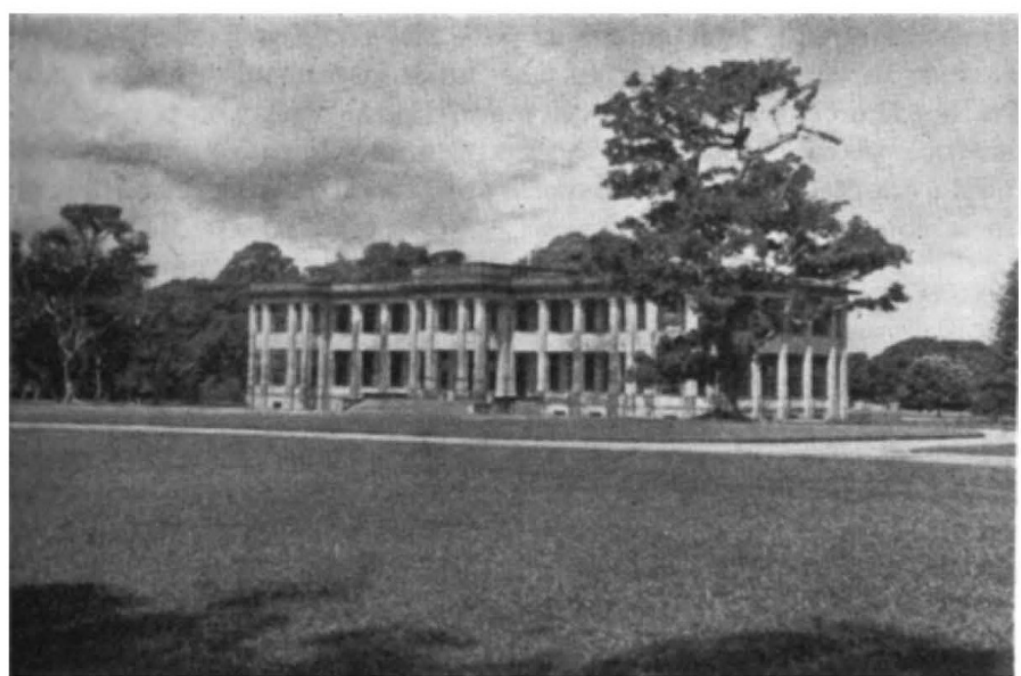

Fig. 1.

Imperial College of Tropical Agriculture: Main Building.

\section{Amenity}

For those to whom the tropic urge has proved irresistible it would indeed be difficult to begin a career in circumstances more favourable than those provided at the Imperial College of Tropical Agriculture. A green and pleasant land, Trinidad provides good living conditions, ample scope for recreation, a wide variety of interests, and, not least, a friendly and kindly people whose hospitality is unstinted. If a man be at all adaptable, he can find in Trinidad most of the things that make for happiness and a sense of life well lived. There must, indeed, be few places in the tropics of which as much can be said.

newly found realm of tropical agriculture, was wealth personified, a veritable El Dorado for the unnumbered generations that would come after.

\section{RAISON D'ETRE}

From Cancer to Capricorn, whether deluged by tropic rain, or starved for water, lies a vast area of which the potential productiveness of the food and commodities that men require has scarcely begun to be realized. But already, because mankind tends to blunder on its myopic way by a process of trial and error, there is much in the sphere of tropical agriculture that is faulty, wasteful and inefficient, and which represents an abuse both of opportunity and material-this in an industry the welfare of which is of fundamental importance to all. For posterity as for our own generation, for all the many peoples scattered over the face of the earth, it is now recognized that the vast resources of the tropics should be treated in no haphazard fashion but should be afforded all the advantages of the accumulated knowledge of agriculture, the steadying guidance of an enlightened administration, and the unstinted assistance of science. To this end the Imperial College of Tropical Agriculture was founded, that its students should go forth to disseminate a new knowledge and idealism to the farthest ends of our great Colonial Empire.
Although it is now more than four hundred years since the first European visitors went to the shores of an island which the aboriginals called Iere - the 'Land of the Humming Bird'-Trinidad is still unspoilt, and for those willing to explore, is a land of adventure and romance. From coast to coast a marvellous profusion of vegetation greets the eye; untouched virgin forests still brood with the solemnity of a thousand years, and the vast gleaming swamps are bright with the plumage of wild fowl. Tucked away in a fold of her green mantle, Trinidad hugs to herself one of the wonders of the world-the Pitch Lake where Sir Walter Ralegh once caulked his ships. Which thought almost tempts us into the byways of digression, for Trinidad possesses a background of remarkable

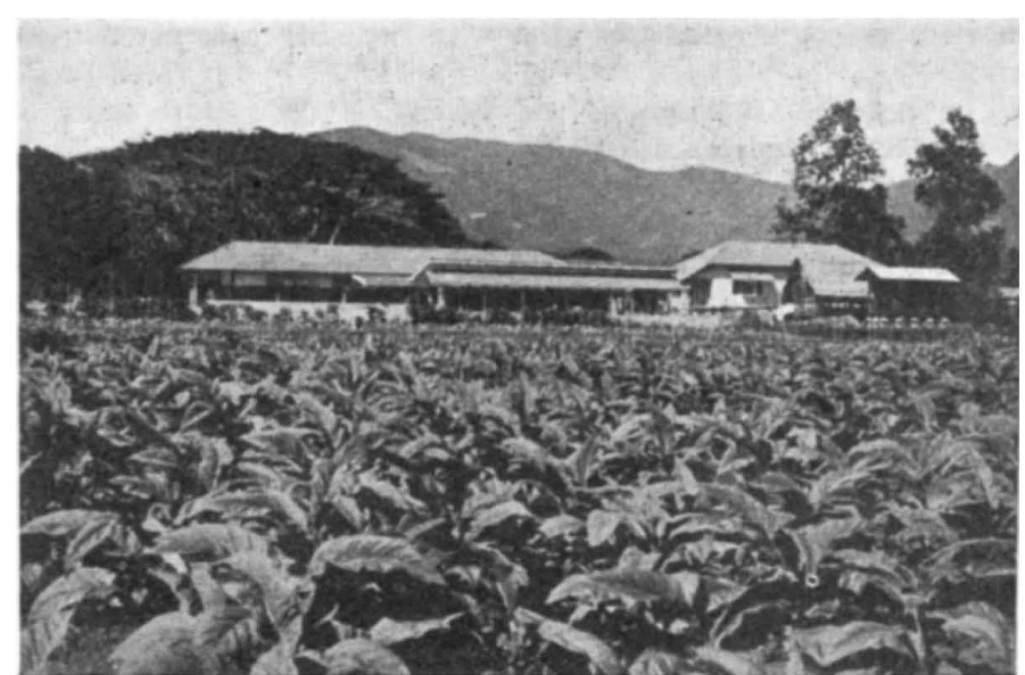

Fig. 2.

Imperial College of Tropical Agrictlture: Farm. Buildings. 
historic interest. Conquistadores were there in olden days, in search of El Dorado, and, in the murky waters of the Orinoco that lave her shores, many hard-fought naval engagements took place. As to her peoples, the island has become the adopted home of many nationalities, and life is colourful and interesting in proportion.

And so we come to the College.

Almost like a university with its atmosphere of detached calm, the College buildings, solid, dignified and with a sense of spacious repose, are set on an expansive savannah, a green pasture, kept trim and orderly, to which shapely angeline and saman trees lend an impression of coolness and grace. Round the savannah are various red-roofed laboratories, students' hostels and staff houses, while beyond, the eye rises to a densely wooded mountain-side cleft by deep valleys, with a Benedictine monastery perched in high seclusion.

\section{DiDACTIC}

The young men destined for the Colonial Agricultural Service are selected with great care from home and dominion universities and from agricultural colleges. As a rule they have already taken an honours degree in science or agriculture, but personality, social qualifications and physique are also considered essential for a service that is as exacting as it is many-sided.

After a year at the Cambridge School of Agriculture, the cadets proceed to Trinidad for a final year of studentship, which initiates them into a great service--the Colonial Agricultural Service. For most of them it must indeed be a wonderful year. The glamour of the tropics, the strange and varied experience of living in a new country peopled with many races, and, not least, the feeling that they are at length coming to grips with their lifework.

The principal function of the College is the instruction of students in tropical agriculture and methods of research relevant to modern agricultural requirements. Accordingly, a closely knit course has been built up over the years whereby the student is given a thorough insight into, or, if he is not a specialist, a good working knowledge of the several sciences which play the part of handmaiden to that vast, comprehensive wholeagriculture.

A knowledge of tropical soils-which are not always as good as the untravelled layman has been led to suppose-is, of course, fundamental. Soils make a whole universe. The problems of their formation, utilization, deterioration and regeneration under the many and varied types of climate and systems of cultivation found between Cancer and Capricorn, the methods of measuring their actual or potential fertility, and of studying the lives of the micro-organisms which inhabit them, are all made the subject not only of discourses in the lecture room, but also of demonstration and experimentation in the field and laboratory.

From the good earth spring the tropical cropsa grand and goodly host of them the variety and abundance of which far exceed the common knowledge of those who have never stirred beyond the confines of temperate lands. So, in his agricultural classes, and with the help of a living museum on the College Farm and in the island as a whole, the student becomes acquainted with the vast array of vegetable commodities that can be produced throughout the equatorial belt : rice, pulses, maize, among cereals ; sugar cane, cotton, tobacco, cocoa, coffee, spices, rubber, bananas and exotic fruits innumerable, oil, fodder, and fibre crops, to mention only a few of the economic plants with which he may have to deal later in his career. But that is only part of the agricultural course. The study of livestock, its care and improvement in the tropics, the use of implemental tillage adapted to different needs and conditions, the methods of field experimentation, and many other aspects of knowledge and practice, all find their place in the curriculum.

As well as being marvellously and variously productive of the goods that man requires, Nature, in her infinite variety, has also at her command the forces of dissolution and decay. Diseases and pests emerge unheralded from the unknown to claim a heavy toll in the domain of agriculture. So in preparation for the maladies which will inevit. ably beset his crops wherever he goes, the student's education includes a survey of fungal diseases and insect pests and the methods by which they can be combated.

Faced with the large assemblage of tropical crops more or less completely new to him, the student, already a botanist, perforce must continue his botanical studies, not merely to familiarize himself with their structure, habitat and mode of life and the influence which different environments exert on their cropping power, but also to consider to what extent, by breeding and selection, new types, more productive, more disease-resistant and more adaptable to different environments can be obtained. Here it may be noted that the College course is so arranged that soil, agricultural, botanical and pathological studies, as well as field demonstrations, are carried out crop by crop in the closest conjunction.

Not last or least, there is instruction in the science of economics, for agriculture, as well as being an art and a science, is also a business. So is there a need for instruction in the methods of economics 
as applied to agriculture in order that the true sources of wealth may be adequately understood, wasteful methods eliminated, and the financial and administrative fabric so adjusted as to make for increasing improvement, not only in the mere matter of pelf, but also in respect of the wider aspects, internal and external, of the social wellbeing of the community.

From this brief and rapid survey some impression may be gained of the wealth of new knowledge and experience that awaits the agricultural cadet. Nor is that all. He also receives instruction in veterinary science, and being himself an animal liable to the ills that beset the empire builder in torrid climes, is duly instructed in the niceties of tropical sanitation and hygiene.

So, at length, after a year that must seem all too short, the student stands forth, as yet inexperienced - $a$ defect which time will rectify-but clad in the armour of knowledge, the torch of science in his hand, ready for service and determined "To strive, to seek, to find and not to yield."

Perhaps, if you travel the world and penetrate into strange and remote places, you may meet old College students. They are to be encountered everywhere throughout the Colonial Empire and Mandated Territories, in East and West Africa, Malaya, New Guinea, the Solomon Islands, British Guiana, the West Indies, Palestine, the Sudan; and they are doing splendid work. This aspect of British Imperial service must be the envy of the world. For while other countries may also possess fine colonies, none, without exception, can boast of such a service, unified by the fellowship that comes from the system of training and the fact that they have one and all studied in the same College. Indeed, the bonds that unite past students not only among themselves but also to their former professors at the College, has through the years created a system of correlated endeavour seldom to be encountered.

\section{Diplomates}

In its attempt to provide men for the agricultural services, official or commercial, the College casts a wide net. With the passage of time a diploma course has been evolved for the instruction of students of school-leaving age who are not proceeding to a university but who desire to qualify for a career in agriculture. These students receive a well-balanced training in the sciences pertaining to agriculture, in the many aspects of agriculture itself, and, if they wish to specialize in that subject, in sugar technology. For the latter purpose there is attached, to the College a model sugar factory, where a thorough training in all matters relevant to the production and preparation of that goodly commodity may be obtained. The members of the diploma course are derived principally from the West Indian islands and British Guiana; but they are also occasionally recruited from regions considerably more remote, while periodic accessions from the French West Indian Colonies and from the Latin American Republics provide a pleasing note of cosmopolitan variety to the College scene.

Diplomates may also play an important part in promoting the welfare of tropical agriculture. They are eligible for appointments in West Indian departments of agriculture, they do important work as sugar technologists, and are recruited as managers or advisers to some of the larger estates.

\section{LIBRARY}

The literature of agriculture, extensive and varied as its theme, cannot be adequately treated in a few words. But suffice it to say that in the College Library there has been assembled not only a comprehensive and representative collection of books, but also a wealth of information in the form of bulletins and memoirs, pamphlets and periodicals, from all parts of the world. Even in the world of letters modern conditions call for speed and efficiency; to meet this need the Library has been indexed and catalogued on a system whereby the information available on any subject can be immediately obtained.

\section{The Scientific Way}

If the way of the agriculturist is hard, he no longer stands alone. In the attempt to control the wayward forces of Nature, the resources of modern science are daily being applied on an increasingly extended front-a campaign in which the Imperial College plays its part, for by its constitution it is an institution for the promotion of research as well as for the propagation of knowledge. Because its functions are imperial, and its work intended to provide information for agricultural officers in their many spheres of activity, the major investigations undertaken fall into that category which may perhaps best be described as 'fundamental applied research'; but local problems are also tackled in collaboration with West Indian Departments of Agriculture.

Of necessity, the crops grown in the West Indies provide the raw material for investigation; but the problems selected for study are such as will tend to elucidate basic scientific principles rather than to yield results of immediate practical importance but of limited application. Not infrequently the research projects call for the collaboration of specialists in different fields. To illustrate a single instance of a College team in action and of the way in which investigators 
throughout the Empire become linked together in a common cause, reference may be made to banana research. Some twelve years ago the heavy losses resulting from the rapid spread of Panama disease-a soil-borne disease of great severity widely distributed throughout the tropics and affecting the Gros Michel banana, the principal variety of commerce-gave rise to a scheme requiring the services of a pathologist to study the malady under field conditions, of a plant breeder whose task was to produce commercial hybrids resistant to the disease, and of a physiologist to investigate the cold storage and ripening behaviour of resistant varieties or hybrids which might be used as commercial substitutes for the Gros Michel. These three sub-divisions of the research programme were centralized at the Imperial College, and among other things led to the construction of plant quarantine houses and of a Low Temperature Research Station. But only part of the story has been told. To search for resistant varieties which might serve as substitutes for the Gros Michel and to provide materials from which desirable hybrids might be obtained, collectors from the Royal Botanic Gardens at Kew were sent to the East, the original home of the banana. In this unusual quest, which still continues, forestry and agricultural officers in remote places have taken a not inconsiderable part. Further, in order that diseases which have attained to epidemic proportions in the Orient might not be introduced into the West Indies, it was necessary to prepare a special quarantine house at Kew and one in Trinidad to provide the necessary safeguards. Meanwhile, in Trinidad, with the passage of time, new and promising hybrids have been raised and their carrying qualities tested, and a vast amount of useful information has been obtained and published on the botany of this important genus, the behaviour of different varieties and hybrids in storage, the basic physiological pro- cesses involved, and on the host of diseases which are liable to cause losses in the field and wastage during transport and ripening. By such a combination of effort it is evident that not only are present needs being served, but also a sure foundation of knowledge is being laid down for the future.

The fascinating story of banana investigations is only one illustration of the many research projects now receiving attention at the College. Reference might equally have been made to work on such crops as cacao, citrus, sugar cane; to storage investigations on exotic fruits; to soil surveys and kindred earthy topics ; to economic probings into the workings of tropical industries and social systems ; and to the many and varied problems of entomology and mycology. Lastly, it may be noted, a special point is made of introducing students to these manifold activities; as a result they go forth, not only with some knowledge of the methods by which problems may be tackled, but also with the feeling that they have, to some extent, become personally identified with researches whose value will become increasingly evident with the passage of time.

In a free world the fruits of knowledge should be available to all. This ideal pervades the work of the Imperial College of Tropical Agriculture. The results of all investigations are published in appropriate journals, and scholarly contacts are maintained with research workers throughout the world. Visitors are made welcome and given the fullest access to such information as they may require. So is the good name of the College being spread abroad, not merely as a scientific adjunct to local aspects of tropical agriculture, but also as a centre of teaching and research where sincerity of scholarship, integrity of purpose, and a realistic vision for the future, must inevitably play a profoundly important part in aidinghumanity in a great practical need-to cultivate its tropical garden.

\title{
THE FOUNDATIONS OF EMPIRICAL KNOWLEDGE
}

\author{
By Prof. Herbert Dingle, \\ Imperial College of Science and Technology
}

$\mathrm{F}_{\mathrm{or}}^{\mathrm{on}}$ R more reasons than one it is important that those who are engaged in acquiring empirical knowledge should sometimes ask what it is precisely that they are doing, and what is the significance of their work. Much depends on the answer to this question, for in the long run it determines the direction which history takes. High explosive and incendiary bombs may destroy the material products of civilization, but if civilization survives it can produce others : a false idea is a bomb of the delayed action type which may destroy civilization itself. For this reason I have on more than one occasion protested against the false notion, coming unfortunately from authoritative sources within the world of science itself, that what we call empirical knowledge can be acquired with- 